\title{
Implementation Of Clinical Pathway For Management of COPD Exacerbation
}

\author{
Alvin Kosasih \\ Pulmonary Hospital Dr. M. Goenawan Partowidigdo, Bogor
}

\begin{abstract}
Corresponding Author:
Alvin Kosasih | Pulmonary Hospital Dr. M. Goenawan Partowidigdo, Bogor |

alvinkosasih@gmail.com
\end{abstract}

Submitted: March $14^{\text {th }}, 2021$

Accepted: March $31^{\text {th }}, 2021$

Published: June $23^{\text {th }}, 2021$

Respir Sci. 2021; 1(3): 166-173

https://doi.org/10.36497/respirsci.v1i3.21

\begin{abstract}
Background: The effectiveness for reducing the length of stay and produce better outcomes has been applied with the use of the clinical pathway. In this study, we observe the implementation of clinical pathways (CP) and evaluate their effectiveness in the management of Chronic Obstructive Pulmonary Diseases (COPD) exacerbation in Goenawan Partowidigdo Pulmonary Hospital (RSPG) Cisarua Bogor.

Method: This research is a quantitative study with an analytical survey method and cross-sectional design. Data collection was carried out by studying documentation on 304 medical record files from early 2019 to July 2020 and clinical pathway forms.

Results: There were differences in clinical outcomes before and after the implementation of CP. The difference in the overall mean length of stay (LOS) using CP were 4 days while the who did not use CP were 6 days. For In-Hospital Mortality (IHM) there was 1 death in the CP group, and there were no deaths in non-CP groups. As for the Readmission Rate (RR), the results of the study showed that the most RR was in the CP group, which were 6 patients (54.5\%) in $1^{\text {st }}$ wards, 5 patients $(62.5 \%)$ in $2^{\text {nd }}$ wards and 39 patients $(70.9 \%)$ in $3^{\text {rd }}$ wards. These RR results showed that CP of COPD exacerbation must be evaluated further. The average total hospital rate showed a significant difference between the two clinical methods. The hospital rate variable had a very significant difference between the $\mathrm{CP}$ and non-CP methods, with a significant value of $=0.0001$.
\end{abstract}

Conclusion: The application of $\mathrm{CP}$ can reduce the length of stay (LOS) and the average total hospital rate of patients who are hospitalized for COPD exacerbation. This CP must be evaluated further to reduce the readmission.

Keywords: clinical pathway, COPD exacerbation

\section{INTRODUCTION}

The main objective of implementing the clinical pathway is to select best practice patterns from a wide variety of practice patterns, establish expected standards regarding the length of care and use of clinical procedures. In addition, the implementation of clinical pathways can be used to assess the relationship between various stages and conditions different in a process and develop strategies to produce faster services with fewer stages. ${ }^{1,2}$

Chronic Obstructive Pulmonary Diseases (COPD) exacerbation are 
characterized by acute patient symptoms such as shortness of breath (dyspnea), cough, and/or purulent sputum, which may improve with routine medication. The GOLD Report 2014 explains that the cost for health due to COPD is $56 \%$ of the total cost to be paid for respiratory diseases. The highest costs are caused by the incidence of exacerbations of this disease. ${ }^{3}$ The incidence of this disease increases with increasing age and is higher in men (4.2\%) than in women $(3.3 \%))^{4}$

\section{METHOD}

The type of this research is quantitative with survey analytic method and cross-sectional. ${ }^{5}$ This research was conducted retrospectively and analyzed descriptively, namely the method of problem-solving which was investigated by describing the current state of the subject or research object based on visible facts or as they are. The medical record of Goenawan Partowidigdo Pulmonary Hospital (RSPG) files used in this study was from the beginning of 2019 to July 2020. The materials used were notes or data on the medical record card taken from RSPG Cisarua which is related to COPD. The data collection technique used a documentation study of 304 medical record files and clinical pathway (CP) forms.

The samples for COPD patients with the implementation of clinical pathways were 152 medical record files and for COPD patients without the implementation of the CP were 152 medical record files. The data analysis method used in this research is quantitative analysis. The hospital outcome analysis was in the form of Length of Stay (LOS) using Mann-Whitney, while the readmission rate (RR) and in-hospital mortality (IHM) used chi-square. Analysis of the outcome of the economy in the form of the total real costs of the two groups using Mann-Whitney.

\section{RESULT}

The results of the statistical analysis of the Mann Whitney difference test were obtained, which showed a very significant difference between the LOS with the CP method with LOS non-CP $(P=0.0001)$. The results of the analysis showed that the average LOS for class 1 using CP was 3.64 days, 1.94 days more efficient than non$\mathrm{CP}$. Other parameters are IHM and RR, the results of the analysis of the two groups showed $P>0.05$, this indicates that there was no significant difference between the two groups.

The average total hospital rate per patient is relatively the same and does not show a statistically significant difference between the two clinical methods (Table 2.) However, in the RS rate variable, there is a significant difference between the $\mathrm{CP}$ and non-CP methods $(P=0.0001)$. The average hospital rate using the $\mathrm{CP}$ method were Rp 1.693.753,00 for each patient.

Likewise, the average rates of nursing, radiology, accommodation rooms and drugs using $\mathrm{CP}$ are significantly more efficient than non-CP. The average efficiency obtained in the nursing, radiology, accommodation room and 
medicine variables were Rp. 318,373,00, Rp. $27,717,00, \quad$ Rp. $698,642,00$ and Rp. $317,286,00$ per patient.

Table 1. Comparison Results of Hospital Outcomes in Class 1 Inpatients with Exacerbation of COPD Cases in RSPG with CP and Non-CP in 2019

\begin{tabular}{lccc}
\hline \multirow{2}{*}{ Outcome RS } & \multicolumn{2}{c}{ Mean } & \multirow{2}{*}{$\mathbf{P}$} \\
\cline { 2 - 3 } & $\mathbf{C P}$ & Non CP & \\
\hline LOS & 3,64 & 5,58 & $0,0001^{* *}$ \\
IHM & $0(0 \%)$ & $0(0 \%)$ & $0,277^{*}$ \\
RR & $6(54,5 \%)$ & $5(45,5 \%)$ & $0,539^{*}$ \\
\hline
\end{tabular}

Note:

$*$ Chi Square Test of significance 0,05

**Mann-Whitney Test of significance 0,05

LOS = Length of Stay; IHM = In-Hospital Mortality; $\mathrm{RR}=$ Readmission Rate

From Table 3, the statistical analysis results are obtained. Mann Whitney difference test, which shows a significant difference between the length of stay (LOS) with the CP and non-CP ( $P=0.0001)$. The results of the analysis show that the average LOS for class 2 using CP is 3.95 days, 1.65 days more efficient than non$\mathrm{CP}$. Other parameters are IHM and RR, the results of the analysis of the two groups showed $P>0.05$, this indicates that there was no significant difference between the two groups.

The RS rate variable has a significant difference between the $\mathrm{CP}$ and non-CP methods $(P=0.002)$. The average hospital rate using the $\mathrm{CP}$ method can be streamlined as much as Rp. 1,086,813,00 per patient. The average efficiency obtained in the nursing variable, accommodation room and medicine, each of Rp. 208,285,00, Rp. 516,304,00 and Rp. 418,964,00 per patient.
Table 3. Comparison Results of Hospital Outcomes in Class 2 Inpatients with Exacerbation of COPD Cases in RSPG with CP and Non-CP in 2019 to 2020

\begin{tabular}{lccc}
\hline \multirow{2}{*}{$\begin{array}{c}\text { Outcome } \\
\text { RS }\end{array}$} & \multicolumn{2}{c}{ Mean } & \multirow{2}{*}{ P } \\
\cline { 2 - 3 } Non CP & \\
\hline LOS & 3,95 & 5,60 & $0.0001^{* *}$ \\
IHM & $1(100 \%)$ & $0(0 \%)$ & $0,317^{*}$ \\
RR & $5(62,5 \%)$ & $3(37,5 \%)$ & $0,315^{*}$ \\
\hline
\end{tabular}

Note:

*Chi Square Test 0.05 significance

**Mann-Whitney Test significance 0,05

LOS = Length of Stay; IHM = In-Hospital Mortality; $\mathrm{RR}=$ Readmission Rate

Table 5 showed the significant difference between the LOS with the CP method and non-CP. The results of the analysis show that the average length of time treated (LOS) for class 3 using CP is 4.12 days, 1.48 days more efficient than non-CP. Other parameters are IHM and $\mathrm{RR}$, the results of the analysis of mortality rates for the two groups showed that there was no significant difference between the two groups.

Table 5. Comparison Results of Hospital Outcomes in Class 3 Inpatients with Exacerbation of COPD Cases in RSPG with CP and Non-CP in 2019 to 2020

\begin{tabular}{lccc}
\hline \multirow{2}{*}{$\begin{array}{l}\text { Outcome } \\
\text { RS }\end{array}$} & \multicolumn{2}{c}{ Mean } & P \\
\cline { 2 - 3 } CP & Non-CP & \\
\hline LOS & 4.12 & 5,58 & $0.000^{* *}$ \\
IHM & $0(0 \%)$ & $0(0 \%)$ & $0,317^{*}$ \\
RR & $39(70,9 \%)$ & $16(29,1 \%)$ & $0,001^{*}$ \\
\hline
\end{tabular}

*Chi Square Test 0.05 significance

**Mann-Whitney Test significance 0,05

LOS = Length of Stay; IHM = In-Hospital Mortality; $\mathrm{RR}=$ Readmission Rate

While the results of repeated analysis of patients from two groups showed $\mathrm{P}<0.05$, this indicates that there was $a$ significant difference between the two groups. 
Table 2. Comparison Results of Economic Output in Class 1 Inpatients with Exacerbation of COPD Cases in RSPG with CP and Non-CP in 2019 to 2020

\begin{tabular}{|c|c|c|c|c|}
\hline \multirow[b]{2}{*}{ Variable } & \multicolumn{2}{|c|}{ Mean } & \multirow{2}{*}{$\begin{array}{l}\text { Mann-Whitney } \\
\text { Statistical Value }\end{array}$} & \multirow[b]{2}{*}{$\mathbf{P}$} \\
\hline & $\begin{array}{c}C P \\
(N=25)\end{array}$ & $\begin{array}{l}\text { Non-CP } \\
(\mathrm{N}=29)\end{array}$ & & \\
\hline Total Tariff / INA CBGs (Rp) & 7.248 .008 & 7.066 .041 & 303.50 & 0.292 \\
\hline Hospital Rates (Rp) & 4.018 .783 & 5.712 .536 & 158.00 & 0.000 \\
\hline Non-Surgical Procedure (Rp) & 14.400 & 10.344 & 360.00 & 0.895 \\
\hline Surgical Procedures & 0 & 0 & 362.50 & 1.000 \\
\hline Experts & 1.680 & 0 & 333.50 & 0.124 \\
\hline Nursing & 617.920 & 936.293 & 237.50 & 0.030 \\
\hline Support & 18.400 & 17.448 & 356.50 & 0.901 \\
\hline Radiology & 104.800 & 132.517 & 250.50 & 0.037 \\
\hline Laboratory & 485.360 & 510.465 & 358.00 & 0.938 \\
\hline Rehabilitation & 27.600 & 82.241 & 273.50 & 0.066 \\
\hline Accommodation Room & 782.000 & 1.480 .642 & 129.00 & 0.000 \\
\hline Drug & 1.540 .444 & 1.857 .730 & 246.00 & 0.043 \\
\hline BMHP & 36.728 & 88.629 & 324.00 & 0.497 \\
\hline Difference in Fare & 3.229 .224 & 1.353 .505 & 181.00 & 0.002 \\
\hline
\end{tabular}

Table 4. Comparison Results of Economic Outcomes in Class 2 Inpatients with COPD Exacerbations in RSPG with CP and Non CP in 2019 to 2020

\begin{tabular}{|c|c|c|c|c|}
\hline \multirow{2}{*}{ Variable } & \multicolumn{2}{|c|}{ Mean } & \multirow{2}{*}{$\begin{array}{l}\text { Mann-Whitney } \\
\text { Statistical Value }\end{array}$} & \multirow{2}{*}{$\mathbf{P}$} \\
\hline & $\mathbf{C P}$ & Non-CP & & \\
\hline Total Tariff / INA CBGs (Rp) & 5.749 .135 & 6.211 .465 & 201.00 & 0.469 \\
\hline Hospital Rates (Rp) & 3.449 .298 & 4.536 .111 & 104.00 & 0.002 \\
\hline Non-Surgical Procedure (Rp) & 0 & 0 & 230.00 & 1.000 \\
\hline Surgical Procedures & 0 & 0 & 230.00 & 1.000 \\
\hline Experts & 1.000 & 2.608 & 211.50 & 0.371 \\
\hline Nursing & 452.475 & 660.760 & 137.00 & 0.024 \\
\hline Support & 69.950 & 29.086 & 181.00 & 0.195 \\
\hline Radiology & 123.350 & 113.913 & 219.00 & 0.766 \\
\hline Laboratory & 549.025 & 542.826 & 208.50 & 0.601 \\
\hline Rehabilitation & 28.250 & 69.782 & 190.00 & 0.252 \\
\hline Accommodation Room & 500.000 & 1.016 .304 & 68.50 & 0.000 \\
\hline Drug & 1.118 .612 & 1.537 .576 & 149.00 & 0.049 \\
\hline Medical equipment & 135.237 & 85.860 & 149.00 & 0.045 \\
\hline Difference in Fare & 2.299 .837 & 1.675 .354 & 170.00 & 0.144 \\
\hline
\end{tabular}

Table 6. Comparison Results of Economic Outcomes in Class 3 Inpatients with COPD Exacerbations in RSPG with CP and Non CP in 2019 to 2020

\begin{tabular}{lcccc}
\hline \multicolumn{1}{c}{ Variable } & \multicolumn{2}{c}{ Mean } & Mann-Whitney & \multirow{2}{*}{ P } \\
\cline { 2 - 3 } & CP & Non-CP & Statistical Value & 0.018 \\
Total Tariff / INA CBGs (Rp) & 4.727 .407 & 5.122 .443 & 435.10 & 0.000 \\
Hospital Rates (Rp) & 2.842 .839 & 3.797 .202 & 317.20 & 0.594 \\
Non-Surgical Procedure (Rp) & 8.971 & 1.440 & 530.25 & 1.000 \\
Surgical Procedures & 0 & 0 & 535.50 & 0.654 \\
Experts & 626 & 560 & 528.90 & 0.000 \\
Nursing & 446.476 & 624.065 & 367.60 & 0.418 \\
Support & 25.794 & 26.300 & 504.00 & 0.939 \\
Radiology & 74.018 & 66.700 & 532.00 & 0.057 \\
Laboratory & 315.757 & 385.785 & 452.00 & 0.971 \\
Rehabilitation & 18.317 & 19.780 & 533.90 & 0.000 \\
Accommodation Room & 322.429 & 439.000 & 354.00 & 0.000 \\
Drug & 1.127 .951 & 1.613 .050 & 325.00 & 0.093 \\
Medical equipment & 95.323 & 158.504 & 463.10 & 0.021 \\
Difference in Fare & 1.884 .568 & 1.325 .241 & 435.00 & \\
\hline
\end{tabular}


Table 6 shows the average total hospital rate per patient showed a significant between the two groups, and the RS rate variable also has a significant difference between the $\mathrm{CP}$ and non-CP methods. Meanwhile, the average hospital rate using the $\mathrm{CP}$ method can be streamlined as much as Rp. 954,363,00 per patient.

Case analysis of patients in the inpatient room class 3 in 2019 to July 2020, was carried out on 17 variables, with an average of nursing variables, accommodation rooms, drugs and difference in rates which showed a significant difference between $\mathrm{CP}$ and nonCP.

Likewise, the average nursing rates, accommodation rooms and drugs using $\mathrm{CP}$ are significantly more efficient than nonCPs. The average efficiency obtained in the nursing variable, accommodation room and medicine, each of Rp. 177,589,00, Rp. $116,571,00$ and Rp. 485,099,00 per patient.

\section{DISCUSSION}

In this study, we compared the results (LOS, RR and IHM) of patients treated using $\mathrm{CP}$ and non-CP from medical record data from 2019 to 2020. This study proves the hypothesis that the use of $\mathrm{CP}$ in the management of COPD exacerbation reduces the duration of hospitalization (LOS). We found a significant reduction in LOS in the CP group compared to the non$\mathrm{CP}$ group in inpatients class 1,2 and 3 . The overall mean LOS of exacerbated COPD patients using $\mathrm{CP}$ was 4 days while the overall mean LOS of exacerbated COPD patients who did not use $C P$ is 6 days. $A$ study by Andrea et al., who utilized exacerbation of COPD, also showed a significant reduction in the mean length of stay of 5 days in the CP group and 7 days in the non-CP group. ${ }^{6}$ The same study was also conducted by Santamaria showing efficiency of 0.89 days (13.2\%) of staying in the hospital using $\mathrm{CP} .{ }^{7} \mathrm{~A}$ retrospective study by Celis et al. (2011) also showed a significant decrease in LOS. ${ }^{8}$

This suggests that the implementation of $\mathrm{CP}$ can reduce the length of stay for patients in the hospital. and will also directly reduce the cost of care. Several things that cause the LOS value in patients to belong include age, disease severity and the presence of comorbidities. ${ }^{9}$ These data are insufficient to demonstrate the optimal duration of hospitalization in patients with exacerbation of COPD. A study on the length of hospital stay required for COPD exacerbation was conducted by Mushlin et al. found that 6.9 days was considered the mean LOS. ${ }^{10}$ The mean LOS that the investigators found was considered effective and efficient because it was past the average recommended antibiotic use period (3 to 7 days) of the GOLD guideline. ${ }^{11}$ This study shows that treating exacerbated COPD patients using $\mathrm{CP}$ can help reduce the length of stay and indirectly reduce patient care costs.

Another parameter is IHM. The results of the analysis of the two groups showed that there was no significant difference between the two groups. There 
was only one patient death in the CP group, namely in the class 2 patient and there was no death in class 1 and 3 in both the CP and non-CP groups. The risk of death in the hospital was independently associated with patient-related factors such as age, presence of respiratory acidosis and CCI. ${ }^{12}$ COPD will have a negative impact on the quality of life of patients, including patients aged $>40$ years will cause the sufferer's disability. Even though they are still in the productive age group but cannot work optimally because of chronic shortness of breath. Comorbidity of COPD will result in cardiovascular disease, bronchial cancer, lung infections, thromboembolism disorder, asthma, hypertension, osteoporosis, joint pain, depression and anxiety. ${ }^{13}$

COPD mortality is higher in males and will increase in the $>45$ years age group. This could be attributed to decreased respiratory function at the age of $30-40$ years 29. Research in America states that COPD is associated with a risk of death which is defined as the hazard ratio (HR). ${ }^{13}$ Apart from the death of the patient in the hospital during treatment, the clinical outcome analyzed was the RR. Researchers did not find a significant difference in recurrent patient admission or RR between the two groups in class 1 and 2 .

Whereas RR in grade 3 patients showed a significant difference between the $\mathrm{CP}$ and non-CP groups. The results showed that the most RR was in the $C P$ group, both in grade 1, 2 and 3. As many as 6 patients (54.5\%) in class 1, 5 patients $(62.5 \%)$ in grade 2 and 39 respectively. patients $(70.9 \%)$ were in grade 3 . The main reason for re-entry in this study was shortness of breath. ${ }^{6}$ The factors that cause the number of patients to return to the hospital are due to the presence of single or multiple comorbidities, inadequate therapy in the $\mathrm{CP}$ group patients, the comparison of the number of specialist doctors with the number of exacerbated COPD patients and the inadequate management of COPD exacerbations, for example, such as treatment of patients that have not been completed. ${ }^{14}$

The mean total hospital rates per patient showed a significant difference between the two clinical methods in both grades 1,2 and $3(P<0.05)$. In addition, the RS rate variable also has a significant difference between the $\mathrm{CP}$ and non-CP methods, with a significance value $P<0.0001$. The average hospital rate using the $\mathrm{CP}$ method can be streamlined as much as Rp. 1,693,753,00 per patient in class 1 , Rp. 1,086,813,00 per patient in class 2 and Rp. $954,363,00$ per patient. With these results, it can be concluded that the application of $\mathrm{CP}$ can reduce the cost of treatment. $^{2}$

Another reason related to the implementation of the clinical pathway is the implementation of the National Health Insurance (Jaminan Kesehatan Nasional/JKN) system that has been implemented since January 2014 by the Health Insurance Management Agency (Badan Penyelenggara Jaminan Sosial/BPJS) using the Indonesian Cased Based Groups (INA-CBGs) tariff. The application of the tariff for the INA CBGs 
package requires hospital management to be able to save costs and optimize hospital financial management, as well as carry out quality control, cost control and access through calculating the cost of care based on the calculation of unit costs owned by the hospital. ${ }^{2}$ Implementation of $\mathrm{CP}$ is an interesting discussion among health workers.

The results of other studies show that there is budget efficiency (cost reduction) after the implementation of clinical pathways. ${ }^{15}$ This is in line with the review of several studies conducted by Rotter et al., the result is that the implementation of clinical pathways can reduce treatment costs by up to \$US 261 from ordinary care (without clinical pathways). ${ }^{16}$

Some of the advantages of implementing the clinical pathway are the uniformity of services and the ease with which the health staff team manages patients. In developed countries such as the UK, America and Australia clinical pathways continue to be developed and have a positive impact on the quality of life of patients, cost efficiency and minimize variations in action. The variations that occur can be in the form of variations in action or variations in the use of drugs. ${ }^{17}$

\section{CONCLUSION}

There are differences in clinical outcomes before and after the implementation of clinical pathways in the treatment of exacerbation COPD disease. The difference in the overall mean length of stay of exacerbated COPD patients using
$\mathrm{CP}$ was 4 days while the overall mean LOS of exacerbated COPD patients who did not use CP was 6 days. In-Hospital Mortality (IHM) there was only one patient death in the CP group, namely in the class 2 patient and there were no deaths in class 1 and 3 in both the CP and non-CP groups. As for the Readmission Rate (RR), the results of the study showed that the most RR was in the CP group, both in grade 1,2 and 3 patients. 6 patients $(54.5 \%)$ respectively in class 1,5 patients $(62.5 \%)$ in class 2 and 39 patients $(70.9 \%)$ in class 3 . The average total hospital rate per patient shows a significant difference between the two clinical methods in both classes 1,2 and 3 . In addition, the RS rate variable also has a significant difference between the $\mathrm{CP}$ and non-CP methods.

\section{REFERENCES}

1. Kinsman $L$, Rotter $T$, James $E$, Snow $P$, Willis J. What is a clinical pathway? Development of a definition to inform the debate. BMC Med. 2010;8.

2. Presiden Republik Indonesia. Peraturan Presiden Nomor 12 Tahun 2013 tentang Jaminan Kesehatan . 2013.

3. Perhimpunan Dokter Paru Indonesia. Penyakit Paru Obstruktif Kronik (PPOK). Pedoman Diagnosis Penatalaksanaan di Indonesia. Perhimpunan Dokter Paru Indonesia. http://klikpdpi.com/index.php?mod= content\&sel=93. Published 2013.

4. Badan Penelitian dan Pengembangan Kesehatan Kementerian Kesehatan 
RI. Penyajian Pokok-Pokok Hasil Riset Kesehatan Dasar 2013. 2013.

5. Sugiyono. Metode Penelitian Kuantitatif Kualitatif Dan R\&D. Bandung: Alfabeta; 2017.

6. Ban A, Ismail A, Harun R, Abdul Rahman A, Sulung $S$, Syed Mohamed A. Impact of clinical pathway on clinical outcomes in the management of COPD exacerbation. BMC Pulm Med. 2012;12(1):1-8.

7. Santamaria N, Conners AM, Osteraas J, Ham J, Boodram B. A prospective cohort study of the effectiveness of clinical pathways for the in-patient management of acute exacerbation of chronic obstructive pulmonary disease (COPD). Collegian. 2004;11(1):12-16.

8. Celis G, Lodewijckx C, Schoonis A, Decramer $M$ (Leuven $B$. Clinical pathway for acute COPD exacerbations reduces hospital stay and readmission rate. Eur Respir $\mathrm{J}$. 2006;28(Suppl. 50):834.

9. Cannon $\mathrm{CP}$, Hand MM, Bahr $\mathrm{R}$, et al. Critical pathways for management of patients with acute coronary syndromes: An assessment by the National Heart Attack Alert Program. Am Heart J. 2002;143(5):777-789.

10. Mushlin AI, Black ER, Connolly CA, Buonaccorso KM, Eberly SW. The Necessary Length of Hospital Stay for Chronic Pulmonary Disease. JAMA J Am Med Assoc. 1991;266(1):80-83.

11. Van Horn L. Elaine R. Monsen, PhD, RD--A Remembrance. J Acad Nutr Diet. 2015;115(8):1342-1344.
12. Hartl S, Lopez-Campos JL, PozoRodriguez $\mathrm{F}$, et al. Risk of death and readmission of hospital-admitted COPD exacerbations: European COPD Audit. Eur Respir J. 2016;47(1):113121.

13. Oemiati, Ratih. Kajian Epidemiologis Penyakit Paru Obstruktif Kronik (PPOK). Media Heal Res Dev. 2013;23(2):82-88.

14. Vanhaecht K, Lodewijckx C, Sermeus W, et al. Impact of a care pathway for COPD on adherence to guidelines and hospital readmission: A cluster randomized trial. Int $\mathrm{J} C O P D$. 2016;11(1):2897-2908.

15. Carlson N, Miller Jr $\mathrm{H}$, Heth $\mathrm{D}$, Donahoe J, Martin G. Psychology: The Science of Behavior. 7th ed. London: 2009. https://www.pearson.com/us/highereducation/program/Carlson-

Psychology-The-Science-of-Behavior7th-Edition/PGM294565.html.

16. Rotter $\mathrm{T}$, Kinsman $\mathrm{L}$, James $\mathrm{EL}$, et al. Clinical pathways: effects on professional practice, patient outcomes, length of stay and hospital costs. Cochrane Database Syst Rev. 2010;(3).

17. Pahriyani A, Andayani TM, Pramantara IDP. Pengaruh Implementasi Clinical Pathway Terhadap Luaran Klinik Dan Ekonomik Pasien Acute Coronary Syndrome. J Manaj dan Pelayanan Farm. 2014;4(3):146-150. 